\title{
Diagnosis of epidermoid lung carcinoma in a patient presenting with skin lesions
}

\author{
Esra Pancar Yuksel ${ }^{*}$, Burcin Celik ${ }^{b}$, Gokhan Sahin ${ }^{a}$, Fatma Aydin ${ }^{\mathrm{a}}$, Nilgun Senturk ${ }^{\mathrm{a}}$, Muge Guler Ozden ${ }^{\mathrm{a}}$, \\ Tayyar Canturk ${ }^{a}$, Ahmet Yasar Turanlia
}

${ }^{a}$ Department of Dermatology, Faculty of Medicine, Ondokuz, Mayis University, Samsun, Turkey

${ }^{b}$ Department of Thoracic Surgery, Faculty of Medicine, Ondokuz Mayis University, Samsun, Turkey

\section{ARTICLE INFO}

\section{Article History}

Received

Accepted

$02 / 04 / 2013$

$27 / 06 / 2013$

\section{* Correspondence to:}

Esra Pancar Yüksel

Department of Dermatology,

Faculty of Medicine,

Ondokuz Mayis University,

Samsun, Turkey

e-mail: esrapancar@yahoo.com

\section{ABSTRACT}

Skin lesions sometimes represent internal diseases or malignancies. Diagnosis of the associated disease could be important for the prognosis of the patient. Linear IgA bullous dermatosis $(\mathrm{LABD})$ is a rare autoimmune subepidermal vesiculobullous disease. Tense vesicles and bullae, sometimes in an arcuate or linear pattern, are seen as the clinical feature. Although associations of various disorders such as gastrointestinal diseases, autoimmune diseases, malignancies with LABD have been reported, it is rare. We report a patient who was diagnosed epidermoid carcinoma of the lung after presentation with tense, annular bullous lesions and didn't respond to prednisolone and dapsone but was treated successfully by neoadjuvant chemotherapy and tumour reduction operation.

J. Exp.Clin.Med., 2013; 30: 251-253

\section{Keywords:}

Epidermoid carcinoma

Linear IgA bullous dermatosis

Operation

Treatment

\section{Introduction}

Linear IgA bullous dermatosis (LABD) is a rare autoimmune subepidermal vesiculobullous disease characterized by the presence of linear $\operatorname{Ig} \mathrm{A}$ deposition along the epidermal basement membrane. Its pathogenesis is not exactly known but drugs and malignancies were found to be related with this disease (Egan and Zone, 1999). Dapsone and prednisolone are the options for the treatment (Sandoval et al., 2012). Although different malignancies have been reported in association with LABD, to our knowledge, we report the first case of LABD associated with epidermoid carcinoma who improved with tumour reduction operation.

\section{Case report}

A 67-year-old man was admitted to our clinic with a twenty days history of eruptions in his body. Numerous tense bullae arranged in an annular configuration on an erythematous background were present on his trunk, arms and legs (Fig.1). There was no mucosal lesion. Nikolsky's sign was negative. He was not on any medication and he had no any known disease. The histopathological examination of a bullous lesion of skin demonstrated subepidermal blister formation. Postero-anterior chest radiography was revealed a consolidation area at the left lower hemithorax. For the evaluation of that consolidation, chest computed tomography (CT) scan and flexible bronchoscopy were performed. Chest CT scan was revealed a mass of $5 \times 6 \mathrm{~cm}$ in size at the left lower lobe and that tumor like lesion invaded neighbouring $6^{\text {th }}$ and $7^{\text {th }}$ ribs. No definite diagnosis was established by bronchoscopic biopsy. Histopathological examination of the CT guided transthoracic biopsy was reported as poorly differentiated epidermoid carcinoma. 


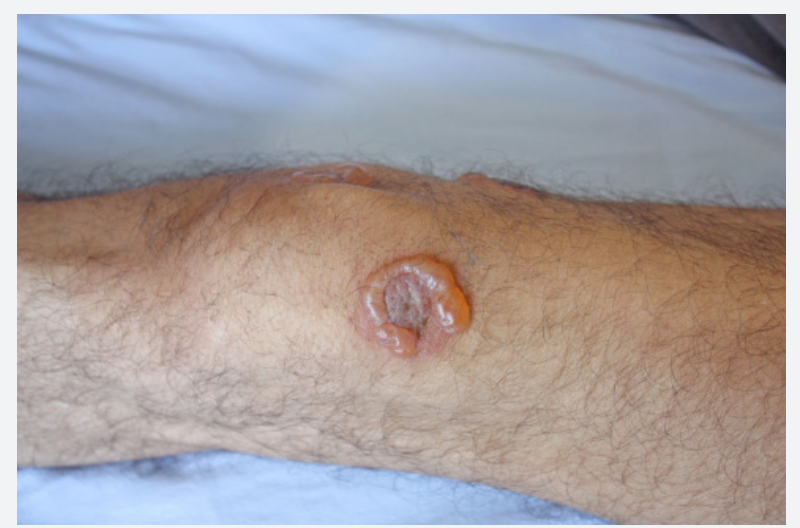

Fig. 1. Tense bullae arranged in annular configuration before tumor reduction operation

The patient was started to be treated with prednisolone $80 \mathrm{mg}$ firstly. Although he was on prednisolone treatment, lesions continued to increase in number. Dapsone $100 \mathrm{mg}$ daily was added to his treatment but controlling the skin lesions could not be possible and dapsone dose was increased to 200 $\mathrm{mg}$ daily. With the diagnosis of epidermoid carcinoma, neoadjuvant chemotherapy then surgery was planned for reduction of the tumour burden of the patient. The prednisolone and dapsone were withdrawn gradually. After neoadjuvant chemotherapy, left lower lobectomy with resection of $6^{\text {th }}$ and $7^{\text {th }}$ ribs was performed through posterolateral thoracotomy (Fig. 2). The postoperative course was uncomplicated, and the patient was discharged on the $10^{\text {th }}$ postoperative day. After the tumour reduction operation his skin lesions disappeared (Fig. 3).

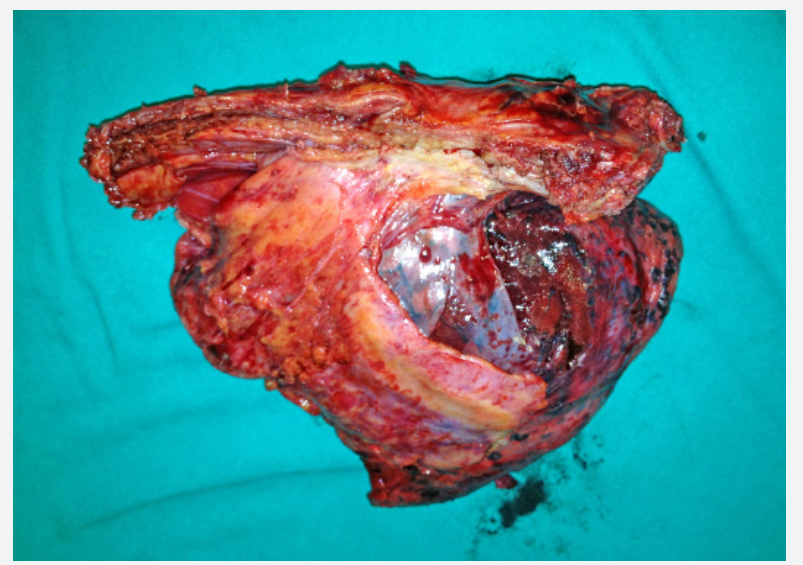

Fig. 2. Left lower lobectomy was performed with resection of $6^{\text {th }}$ and $7^{\text {th }}$ ribs

\section{Discussion}

LABD is an autoimmune disease which the antibody deposition leads to the loss of adhesion at the dermal-epidermal junction so to the blister formation. Tense vesicles and bullae, sometimes in an arcuate or linear pattern are seen on trunk and limbs but generalized blistering is a rare finding as the clinical feature. Mucosal involvement of oral cavity is frequent in adults (Van der Waal et al., 2001). In our case, tense bullae annular in shape were present with a tendency to increase in number despite the medical treatment.

Very few cases of LABD associated with malignancy have been reported. Lymphoproliferative malignancies are the most frequent ones (Barnadas et al.,1988; Godfrey et al.,1990; Kano et al., 1999; Usmani et al., 2004). Among those reports, the relationship between LABD and lymphoproliferative malignancies was evaluated in different manners. Godfrey et al remarked the statistically significance of three cases of lymphoproliferative malignancy in 70 patients of LABD by comparison with an age- and sex-matched population (Godfrey et al., 1990). But the others questionized this association whether it is consistent or fortuitous (Egan and Zone, 1999; Sandoval et al., 2012). Usmani et al pointed out the B-cell origin of tumours and claimed that LABD could be related with an abnormal immune process seen in lymphproliferative disorders (Usmani et al., 2004). Visceral malignancies such as bladder cancer, esophagus cancer, renal cell carcinoma, adenocarcinoma of ascending colon were also reported as being associated with LABD (Green and Natarajan, 1987; Rodenas et al., 1997; Van der Waal et al., 2001). But relationship between $\mathrm{LADB}$ and these malignancies remains also controversial.

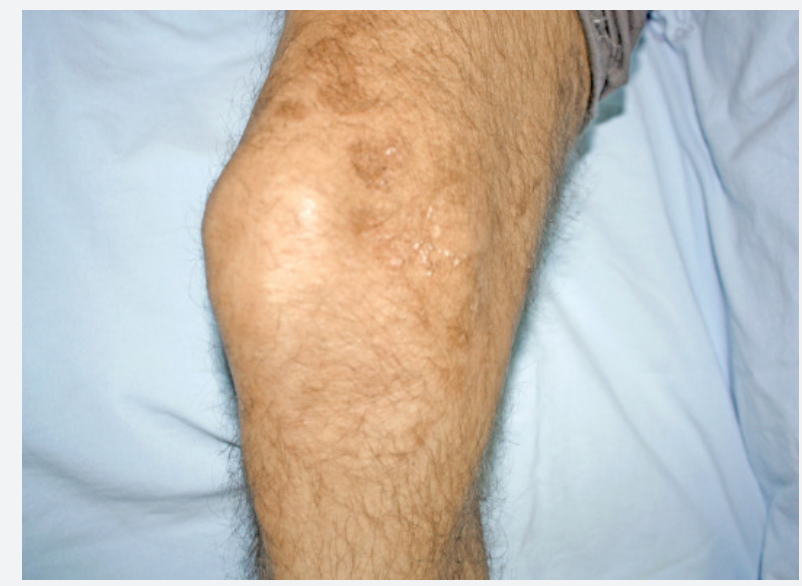

Fig.3. Skin lesions were disappeared after the tumour reduction operation

In our patient the difficulty in controlling the blistering eruption and new lesion formation despite being on dapsone and prednisolone treatment led us to think an association of a malignancy. Researching the consolidation on the postero-anterior chest radiograph made us to diagnose the patient as a lung cancer. Although our patient complained about only skin lesions without any symptom related with pulmonary system, he could be diagnosed as epidermoid carcinoma. So, our case also showed that lung cancer could manifest itself with only skin blisters.

We couldn't manage the disease with medication for LABD, but the lesions resolved completely after the operation for decreasing the tumour burden. Parallel nature of the amount of the lesions and the tumour in our patient, support the significant association between these two conditions. Deterioration of LABD with progression of the malignancy and persistent but less severe cutaneous lesions with palliatively treated metastatic carcinoma were reports that also suggest the close relationship between LABD and malignancies (Usmani et al., 2004; Lai-Cheong et al., 2007). Our case is also important for showing the succeed of the operation for malignancy in treatment of LABD. 
The relationship between the cause of the induction of Ig A synthesis and malignancy might explain whether this association is meaningful or not in LABD patients. We believe that detection and reporting of each new case are of great value in order to clarify the role of malignant cells in the pathophysiology of LABD.

\section{REFERENCES}

Barnadas, M.A., Moreno, A., Brunet, S., González, M.J., Rodriguez, J.L., Gelpí, C., de Moragas, J.M., 1988. Linear IgA bullous dermatosis associated with Hodgkin's disease. J. Am. Acad. Dermatol. 19, 1122-1124.

Egan, C.A., Zone, J.J., 1999. Linear IgA bullous dermatosis. Int. J. Dermatol. 38, 818-827.

Green, S.T., Natarajan, S., 1987. Linear IgA disease and oesophageal carcinoma. J. R. Soc. Med. 80, 48-49.

Godfrey, K., Wojnarowska, F., Leonard, J., 1990. Linear IgA disease of adults: Association with lymphoproliferative malignancy and possible role of other triggering factors. Br. J. Dermatol. 123, 447-452.

Kano, Y., Kokaji, T., Shiohara, T., 1999. Linear IgA bullous dermatosis in a patient with acute lymphocytic leukemia: Possible involvement of granulocyte colony-stimulating factor Eur. J. Dermatol. 9, 122-125.

Lai-Cheong, J.E., Groves, R.W., Banerjee, P., 2007. Linear IgA bullous dermatosis associated with adenocarcinoma of the ascending colon. J. Eur. Acad. Dermatol. 21, 978-979.

Rodenas, J.M., Herranz, M.T., Tercedor, J., Concha, A., 1997. Linear IgA disease in a patient with bladder carcinoma. Br. J. Dermatol. 136, $257-259$.

Sandoval, M., Farias, M.M., Gonzalez, S., 2012. Linear IgA bullous dermatosis: Report of five cases in Chile. Int. J. Dermatol. 51, $1303-1306$.

Usmani, N., Baxter, K.F., Child, J.A., Sheehan-Dare, R., 2004. Linear IgA disease in association with chronic lymphocytic leukaemia. Br. J. Dermatol. 151, 710-711.

Van der Waal, R.I., Van de Scheur, M.R., Pas, H.H., Jonkman, M.F., Van Groeningen, C.J. Nieboer, C., Starink, T.M., 2001. Linear IgA bullous dermatosis in a patient with renal cell carcinoma. Br. J. Dermatol. 144, 870-873. 